\title{
A MEASURED EDUCATIONAL EXPERIENCE DEVELOPING CREATIVITY WITH GRADUATE AND UNDERGRADUATE ENGINEERING STUDENTS
}

\author{
Sophie Morin \\ Polytechnique Montreal \\ sophie.morin@polymtl.ca \\ Jean-Marc Robert \\ Polytechnique Montreal \\ jean-marc.robert@polymtl.ca \\ Liane Gabora \\ University of British Columbia \\ liane.gabora@ubc.ca
}

\begin{abstract}
Creative and innovative people are recognized for their contribution to society's wellbeing. Engineers are often called upon to produce innovative ideas and thus participate in the improvement of their organization's products, services, and processes. Not aiming at educating specialists with a degree in creativity, we nonetheless believe future engineers could benefit from a deliberate development of their creative abilities. However, building an effective and valid course to develop participants' creativity is not without challenges.

This paper describes an innovative cognitive approach to enhance creativity as well as the pedagogical strategies underlining a creativity course for engineering students. It also presents the pre-post results measured with a revised version of the CEDA (Creative Engineering Design Assessment). We evaluated the creative performance of 59 students before and after a 45-hour creativity course. Quantitative data shows statistically higher numbers after the course than before. Qualitative data provides further evidence of the course's relevance and effectiveness.

We conclude that students' creativity can be increase and that the course enables a better understanding of creativity and how to foster it.
\end{abstract}

Keywords: Creativity in engineering, Teaching Creativity, Framework to develop creativity, Creativity course experience

\section{INTRODUCTION}

Increasingly, organizations seek creative engineers to maintain a competitive edge. Creativity enables innovation; it enhances the design and development of new products, processes, or services which should help to insure the profitability of organizations. The literature covering the developmental aspect of creativity is extensive [1]. Creativity programs are increasingly popular. So much so that a new "school of creativity science" was opened in Montreal in 2016. It is widely believed that creativity education can be highly effective and that society would benefit from more programs [2-5]. Just a few programs have a solid theoretical foundation, and scientific evidence of their effectiveness is lacking [69]. Engineers would certainly benefit from such a learning $[10,11]$. However, creativity as a learning object is currently not part of engineering programs [12].

A meta-analysis of 70 training programs, identified key instructional strategies and concepts taught in creativity programs $[13,14]$. The authors identified metatheoretical frameworks, core processes, training techniques, course design variables, medias, exercises types. In each category, they identified which elements appeared to be most effective. The background work carried out within this study facilitated understanding of how creativity development can unfold. The researchers reported the effectiveness of these components, and they made four main recommendations that stand out as an interesting basis for further research on how to help creativity development; (1) Training based on valid conception of the cognitive activities underlying creative efforts, (2) Lengthy, relatively challenging with various 
discrete cognitive skills, and associated heuristics, (3) Articulation of principles should be followed by illustrations of their application using material based on 'real-world' cases or other contextual approaches, (4) Presentation should be followed by a series of exercises appropriate to the domain at hand.

Scott's results show how diverse creativity development can be in specific, real life experiences, but it does not relate those findings to the literature on creativity knowledge and skills, as is needed to link theoretical understanding of creativity with practical skills. The present study outlines a creativity course including theoretical framework, pedagogical activities supporting cognitive skill development and knowledge acquisition, and the quantitative and qualitative measurement of the course's effectiveness.

\section{THEORETICAL FRAMEWORK}

Sawyer [15] presents a list of 10 universities worldwide offering programs (certificate, minors, etc.) on creativity. We found that explicit information on the frameworks, the operational details, the pedagogical strategies and media, used to build these programs was scarce. Few of them appeared to be based on a solid conceptual and theoretical framework.

In some cases, creativity is included within the Project Based Learning (PBL) approach [16]. Creativity is not considered a central learning objective, but rather a quality or an asset, an advantage in the context of the project. Most often, creativity is underestimated as a learning object and even more as a skill to develop [10, $16,17]$. In her recent research, Daly [16] found that even when educators had the intention to foster creativity and thought they used appropriate strategies, students were not perceiving those efforts as such. If creativity is not addressed directly to develop its process, it will remain tacit.

\subsection{Conceptual and process models}

Creative behaviors, products, individuals, have been widely studied, and models of the creative process have been proposed [1, 18-25]. These models focus on particular elements, such as thinking skills, personality traits, environmental and social characteristics, as well as cognitive components that influence creativity. The models although quite different, gather common elements. Four are inherent to the individual (general and creativity knowledge, intrinsic motivation, cognitive skills and tolerance for ambiguity), one to the environment (supportive), and the sixth refers to integration of the others.

Researchers have also studied and defined creativity from a process or procedural viewpoint, i.e. the steps or phases someone goes through when involved in a creative process. From the famous 4-step model of Wallas (preparation, incubation, illumination, verification) to the most recent one (up to 8 steps; Ask, Learn, Look, Play, Think, Fuse, Choose), many variants exist.

With these conceptual and process models in mind, one can anchor a creativity course more firmly on a theoretical basis. Not only does the course address and develop conceptual elements about creativity but it also allows students to engage in particular steps of the creative process.

\subsection{Cognitive abilities}

Identifying, understanding and learning cognitive abilities supporting creativity seem a promising avenue for pedagogical issues. To achieve this, we needed a model describing cognitive abilities, the Cattel-HornCarroll model.

Three broad abilities from the model are particularly associated with creativity (Fluid reasoning, Comprehension-Knowledge, Long-term storage and retrieval). Even though the matter is still debated, we support the idea that the creative process uses general cognitive processes rather than exclusive ones. Specific cognitive abilities are clearly more sought by the creative process than others, but they remain part of a global, general model of intelligence. In other words, particular cognitive abilities are more solicited during a creative process but are not reserved for it, they could be used in other contexts.

We believe that with these cognitive abilities, the CHC model is an appropriate and promising avenue to better understand creativity at a cognitive level [26] and by doing so, build relevant and effective educative strategies.

These three perspectives of theoretical models (conceptual, process, cognitive), all generate interest when developing learning strategies towards increasing an individual's creative potential. We used a combination of these models to anchor our creativity course in a wide ranged theoretical background.

\section{STUDY DESIGN}

An intervention study-in which research and intervention take place simultaneously-was planned with a multi-method quantitative/qualitative descriptive design. A 45-hour course was created, IND8108 Creativity in applied sciences and engineering.

An ethical certification was obtained for the project. Students who took the course were asked to sign a consent form to participate in the pre-post study. The consent form informed the students that the test would be assess by the teacher and that anonymity could not be preserved for the quantitative data but would be for the qualitative data. Also, students could decline participation without prejudice. 


\subsection{Participants}

Fifty-nine engineering students participated to the study. The course is available as an elective to all graduate students and to undergraduates who choose the 'Technological Innovation' orientation at Polytechnique Montréal (an orientation is a set of four courses at the student's discretion in the last 2 years of a 4 years program). The study was done over 3 semesters (Fall 2014, Winter and Fall 2015). They studied in diverse fields of engineering (chemical, industrial, physics, mechanical, etc.)

Table 1: Sample description.

\begin{tabular}{|l|c|c|c|}
\hline \multicolumn{4}{|c|}{ Sample description } \\
\hline \hline Criteria & $\begin{array}{c}\text { Sem.- } \\
\text { Fall '14 }\end{array}$ & $\begin{array}{c}\text { Sem. - } \\
\text { Winter ' } 15\end{array}$ & $\begin{array}{c}\text { Sem. - } \\
\text { Fall '15 }\end{array}$ \\
\hline \hline \# of students & 9 & 22 & 28 \\
\hline $\begin{array}{l}\text { Genders } \\
\text { (F; M) }\end{array}$ & $4 ; 5$ & $10 ; 12$ & $14 ; 14$ \\
\hline $\begin{array}{l}\text { (Grads; } \\
\text { Undergrads) }\end{array}$ & $9 ; 0$ & $7 ; 15$ & $7 ; 21$ \\
\hline $\begin{array}{l}\text { Age } \\
(20-29 ; 30-39 ; 40-49)\end{array}$ & $7 ; 1 ; 1$ & $18 ; 4 ; 0$ & $24 ; 3 ; 1$ \\
\hline
\end{tabular}

\subsection{Creativity Assessment}

During the second week of the course, the CEDA test was administered to the participants to establish initial values of each criterion of the test and to capture a first score of creativity. During the $13^{\text {th }}$ week, the same test was administered again to compare the results of each participant with those obtained at the beginning of the trimester.

The CEDA test was developed by Charyton and her colleagues [27-30]. The test is based on the Purdue Creativity Test (PCT), and adapted for an engineering population. It consists of three design problems (design that can produce sound, design that can facilitate communication, design that can travel) with two, three and four shapes which serve to 'inspire' the participants (cylinder, ball, cube, pyramid). For each problem, two designs should be provided and described according to five aspects: sketch, description, materials, other problems solved, and users. Participants receive one document containing guidelines and the three problems (4 pages).

Even though we made modifications to the assessment process, the theoretical basis underlying the test rests on key elements typically used to measure creativity (divergent thinking, convergent thinking, constraint satisfaction, problem finding, problem solving), we concluded that the CEDA remained a relevant instrument.

Two judges assess fluidity (number of answers) and flexibility (number of different answers) quantitatively by counting different elements (number of materials, of users, of designs, etc.), and they assess originality and usefulness qualitatively on Likert scales. Several changes were made to the original assessment process suggested by Charyton (the global score for each problem was eliminated, the global score for the test was dismissed). The test's reliability was tested and confirmed with the statistical method "gage R\&R". Also, the different levels on Likert scale were discussed and further defined to help the judges make their assessments. The detailed description of these modifications and their justifications are subject to another article [31].

\subsection{Data Collection}

The test was presented to the students as a creativity exercise. At first, the guidelines were read out loud. We did not explain how the exercise would be assessed, and did not mention they would do it a second time two months later. We thought it would influence the results. Every pre-test was given in the 3rd week of the semester and every post-test in the 15th week for the three semesters. All pre and post tests were coded as pairs. Keeping the scores of the four criteria independent would allow us to calculate the difference between the pre and the post test of each participant.

Students' feedback about their experience of the course was obtained through an anonymous online forum. They were invited to answer three open questions (Q1: Is a course like IND8108 relevant in an engineering curriculum? Why?, Q2: Explain if and why your perception of creativity has changed since the beginning of the course, Q3: Do you think you'll be able to use what you learned (knowledge and skills) during the course in a future job setting? How or why not?). The questions were elaborated by the three researchers. Answers were transcribed from a web-based platform. Each question was considered as a category and free coding was done. Synthesis of each subcategory were written [32].

\section{RESULTS}

\subsection{Theoretical work}

The cognitive abilities identified in the theoretical framework were used to perform other creative activities in the course as presented in the table below.

Table 2: Pedagogical strategies.

\begin{tabular}{|l|l|l|}
\hline Pedagogical Activities & Description \\
\hline $\begin{array}{l}\text { In-class } \\
\text { activities }\end{array}$ & $\begin{array}{l}\text { Warm-up } \\
\text { exercises }\end{array}$ & $\begin{array}{l}\text { 30 min at the beginning of } \\
\text { every class, cognitive } \\
\text { exercises, ind. and group }\end{array}$ \\
\cline { 2 - 4 } & $\begin{array}{l}\text { 'Mouse } \\
\text { Trap' project }\end{array}$ & $\begin{array}{l}\text { hours, group project, } \\
\text { build a Rube Goldberg } \\
\text { machine with recycled } \\
\text { materials }\end{array}$ \\
\cline { 2 - 4 } & $\begin{array}{l}\text { Lectures/ } \\
\text { Discussions }\end{array}$ & $\begin{array}{l}\text { Discussions about factors } \\
\text { influencing creativity, } \\
\text { myths and truths, }\end{array}$ \\
\hline
\end{tabular}




\begin{tabular}{|c|c|c|}
\hline & & definition of creativity, etc. \\
\hline & $\begin{array}{l}\text { Creativity } \\
\text { approaches }\end{array}$ & $\begin{array}{l}\text { Peer learning (teams of 3- } \\
\text { 4) (theory/exercise) }\end{array}$ \\
\hline \multirow[t]{2}{*}{ Projects } & $\begin{array}{l}\text { Personal } \\
\text { project }\end{array}$ & $\begin{array}{l}\text { Individual project, students } \\
\text { choose their subject (out of } \\
\text { engineering) }\end{array}$ \\
\hline & $\begin{array}{l}\text { Engineering } \\
\text { (scientific) } \\
\text { project }\end{array}$ & $\begin{array}{l}\text { Group project, students } \\
\text { choose an engineering/ } \\
\text { scientific problem }\end{array}$ \\
\hline \multirow[t]{3}{*}{$\begin{array}{l}\text { Personal } \\
\text { Work }\end{array}$} & Logbook & $\begin{array}{l}\text { Individual task, ongoing } \\
\text { through the semester, } \\
\text { students note observations, } \\
\text { ideas, problems, etc. }\end{array}$ \\
\hline & $\begin{array}{l}\text { Creative } \\
\text { behaviors/ } \\
\text { Forums } \\
\end{array}$ & $\begin{array}{l}\text { Ongoing through the } \\
\text { semester, posting on the } \\
\text { course's website }\end{array}$ \\
\hline & $\begin{array}{l}\text { Scientific } \\
\text { texts }\end{array}$ & $\begin{array}{l}\text { Individual reading, group } \\
\text { discussion with guided } \\
\text { questions (e.g., Lubart, } \\
\text { Ward, Kauffman, Gabora) }\end{array}$ \\
\hline
\end{tabular}

To link the course with the theoretical framework, we matched pedagogical activities with Scott's recommendations $[13,14]$ as well as elements from the conceptual $[1,18,19]$ and process models of creativity [33].

The 'warm-up' period responds to the need to build the course on a "valid conception of the cognitive activities underlying creative efforts' [13]. Serious games are used to play, think and fuse. They allow students to develop and practice cognitive, thinking skills related to making connections. Exempt from particular context, students are invited to draw maps, invent stories, find similarities, play with words, etc. During these activities, great importance is placed on metacognition by sharing everyone's ideas and reflecting on the various processes used to come up with these ideas [34]. Students become more aware of their own process and others can benefit from the exchanges. Every week, simple exercises allow participants to practice and improve basic cognitive abilities associated with the creative process. The games prepared for the course are inspired by the book Zig Zag [33], television programs, board games, creativity tests, and the researcher's personal insights from analyzing creativity literature $[35,36]$ (eg.: Password, Droodles, What's that for?, Draw me a map, What's the story?, etc.). Different criteria were considered when choosing and organizing these games: varied, simply played, easily explained, quickly understood, fun to play. Socioconstructionism is an important basis for the pedagogical approach [37, 38]. During these games, the professor acts as a guide to structure the discussion around the games' cognitive and metacognitive aspects. All these games could be (and may have been) played in other circumstances. The course's added value is the link with the creativity context, the cognitive abilities involved and the relevancy to practice these cognitive processes to achieve a certain ease.

The 'Mouse Trap' project allows students to practice, hands-on, conception and construction skills in a very open engineering context. The project allows everyone to work as a team, in a supportive environment. They have to take risks and tolerate ambiguity when plan A doesn't work. Also, the project allows them to 'make' something, plan and adjust iteratively during the seven hours allocated to the activity. They must persevere throughout the construction/conception challenges, and rapidly find 'homemade' solutions. Engineers should be able to react fast; blueprints are not always the answer and resourcefulness is an important skill to develop. Moreover, it helps students understand and develop a more physical side of creativity.

The principal objective of the forum on creative behaviors is to relate creativity to 'real-world' examples. It allows students to learn more about creativity itself as well as about different domains displaying creative behaviors. Lateral or horizontal knowledge is important to promote and foster remote associations. The forum also helps students develop their observation skills. Knowing how to observe and notice things, people, places, behaviors, etc. is an essential part of developing creativity

During the 15-week semester, two projects are accomplished: a personal and a group project. The personal project is in an area of interest for the student (eg.: painting, cooking, singing, building a game, writing poems, designing a lamp or a shelf, etc.), outside his/her usual domain of competency. It gives rise to a report which should explain the steps of the creative process, to help students reflect on their own creative process, understand it, and thus facilitate its replication and optimization.

The group project is closer to the engineering field without being restrictive (eg.: how to make establishments more accessible for wheelchairs, diminish or eradicate planned obsolescence). The important thing is that the subject is determined by the students themselves and motivates them. The instructions are to suggest solutions to the identified problem by combining ideas from different areas and to use approaches that stimulate creativity as discussed in class. Deliverables are identical to the first project.

An important factor for creativity is the ability to observe our environment and be inspired by it $[39,40]$. With this attitude in mind, students are asked to take notes of observations, facts, impressions, thoughts, etc. that cross their mind daily. The logbook helps to develop critical thinking. Moreover, because working memory has a limited capacity [41], the logbook frees up space by using the principle of distributed cognition [42] i.e. it helps to create an external memory.

Students are asked to research on different approaches to stimulate creativity (e.g., brainstorming and its 
variants, the six hats, bionics, SCAMPER, etc.). In an oral presentation of 15-20 minutes in class, they present one approach theoretically and add a practical exercise. They also submit a one-page document providing a summary of key elements.

Knowing how the approaches cognitively work may support students to use any of them instead of focusing on learning one in particular. It is then possible to surpass the 'recipe' level and understand why, when and how these approaches work (or not).

\subsection{Quantitative results}

From our experience, everyone took the test seriously and wanted to perform well. However, it posed as a challenged not being able to give students feedback between the two tests. Being in a graduate course context, students (also the participants) were curious to know what the "exercise/test" was for and how they did. Giving them this information, would potentially modify their answers for the post test and thus impact the results so we had to keep the explanations to a minimum.

Mean and standard deviation (SD) were obtained for CEDA's each criterion to estimate the magnitude and scattering of the data.

Table 3: Pre-Post values of each criteria.

\begin{tabular}{|c|c|c|c|}
\hline Data & Pre & Post & Criterion \\
\hline Ave. & 40,03 & 44,08 & \multirow{2}{*}{ Fluidity } \\
\hline$\sigma(\mathrm{SD})$ & 10,86 & 11,16 & \\
\hline Ave. & 35,27 & 39,12 & \multirow{2}{*}{ Flexibility } \\
\hline$\sigma(\mathrm{SD})$ & 9,05 & 9,98 & \\
\hline Ave. & 12,56 & 14,87 & \multirow{2}{*}{ Originality } \\
\hline$\sigma(\mathrm{SD})$ & 5,48 & 5,51 & \\
\hline Ave. & 9,86 & 11,66 & \multirow{2}{*}{ Usefulnes } \\
\hline$\sigma(\mathrm{SD})$ & 4,02 & 3,28 & \\
\hline
\end{tabular}

The data was analyzed with paired t-test for each criterion. The results are presented in the Table 4. Normal distribution was respected according to the three tests used. As the $\mathrm{p}$ numbers demonstrate, all four criteria show a slight, but significant increase in values.

Table 4: Paired t-tests results.

\begin{tabular}{|c|c|c|r|l|}
\cline { 2 - 5 } \multicolumn{1}{c|}{} & \multicolumn{4}{|c|}{ T-Test (paired) } \\
\cline { 2 - 5 } \multicolumn{1}{c|}{} & t-value & \multicolumn{1}{c|}{$\mathrm{df}$} & \multicolumn{2}{c|}{$\mathrm{p}$ (unilateral) } \\
\hline \hline Fluidity & -2.62 & 58 & 0.006 & $\%$ reject $H_{0}: 1.13$ \\
\hline Flexibility & -2.95 & 58 & 0.0025 & $\%$ reject $H_{0}: 0.45$ \\
\hline Originality & -3.06 & 58 & 0.0015 & $\%$ reject $H_{0}: 0.33$ \\
\hline Usefulness & -3.58 & 58 & 0.0005 & $\%$ reject $H_{0}: 0.07$ \\
\hline
\end{tabular}

\subsection{Qualitative results}

Thirty of the 59 students who completed the course answered a non-mandatory anonymous forum of three open-ended questions about the course.

From Q1, we found elements justifying the course's relevance from a need, a learning and a curriculum point of view. In Q2, the answers provided information that the students' perception towards creativity had changed as well as their knowledge and skills. Finally, Q3 gave us evidence that the learnings were both theoretical (new tools) and personal (personal effects).

The participants had a positive experience of the course saying that it was different from other engineering courses. They also wrote that the course was useful because they were already using knowledge and skills in other courses' project/work. However, they also mentioned encountering time and motivation challenges when doing so. They said that they acquired new knowledge, new perspectives, and a new understanding of creativity, as well as new strategies to stimulate creativity as the logbook and other metacognition strategies as specific approaches. Some comments brought up that the course would not appear relevant to all engineering students.

Concerning the comments about the CEDA, 17 participants answered (out of 59). Opinions were divided on many aspects. Some didn't agree on the representativeness of their creativity performance offered by test (4/17). Because the course doesn't focus specifically on 'engineering creativity', students felt they acquired a lot more knowledge and developed more skills than the test assessed. A minority of students (6/17) said it was difficult to be motivated by such an exercise. Another challenge was 'fixation'; for some students $(5 / 17)$, even after 11 weeks, they remembered quite well what they had produced the first time, which made it more difficult to think of new solutions. Nevertheless, we believe the CEDA can provide an effective initial exercise to establish important theoretical boundaries (flexibility, fluidity, problem finding, etc.).

\section{DISCUSSION}

\subsection{Pedagogical strategies}

Using conceptual and procedural models to choose and develop pedagogical strategies led to the construction a course anchored on a theoretical basis. The implications of the $\mathrm{CHC}$ model are widespread across the course. The broad abilities 'Fluid reasoning' and 'ComprehensionKnowledge' are solicited during several (if not all) activities. In the first case, deductive reasoning and induction are involved when solving a problem (e.g., accomplishing a personal and a group project, answering questions about scientific texts, etc.). In the second case, it involves the extent of lexical (words), cultural, language 
and general (verbal) knowledge. To make interesting creative connections, extensive lateral knowledge is essential. New knowledge (general and towards creativity) is acquired during numerous activities planned in the course. Communication skills (listening and talking) are also part of this broad ability and frequently practiced during the activities (oral presentations of approaches, open discussions in class, etc.). And finally, the 'Long-term storage and retrieval' broad ability is mostly engaged when playing the warm-up games. Narrow abilities (e.g., Ideational fluency, Associational fluency, Expressional fluency, Naming facility, Word fluency, Figural fluency, etc.) from this category seem to be implicated when constructing mind maps, identifying similarities between words and images, or elaborating a story from a picture. More research is needed along these lines to better understand and define the precise correlations.

\subsection{Quantitative and qualitative data}

Our success in recruiting graduate and undergraduate students from different programs of an internationally recognized school of engineering for an elective course on creativity indicates that from students' perspective there is an interest for this subject. From these quantitative and qualitative results, positive conclusions can be drawn. We observe a statistically significant increase in the four criteria assessing creativity by the CEDA test. Even though the increase is small in number, fluidity, flexibility, originality and usefulness all show improvement when comparing pre-post results. Despite many questions surrounding the CEDA and its use, these results are very encouraging.

Qualitative results show a great need and interest for the course. Students feel they learn useful information about creativity and tools to foster it. They appreciate the openness during discussions and the metacognitive approach used to reflect on their creative process. The lessons are often made where everybody in the group can share knowledge, vision and opinions. They feel free to share their experiences and therefore contribute to the learning process. This provides a richer experience than when the teacher is the only one 'delivering' knowledge.

\subsection{Limitations and future work}

A limitation of this project was the short duration of the course: only 15 weeks. For these cognitive abilities to stay anchored and useable by the learners, continuous practice is important $[15,33]$. Therefore, a more ambitious development program could be considered.

Another limitation is the short period used to measure the effect. Because our study does not follow the students after the course to assess their creativity practice and results one could question its ecological validity. It would be interesting to widen the scope to investigate whether the students become more effective innovators in their future workplaces.

An interesting avenue to explore would be to better understand the links between the development of specific narrow abilities in $G l r$, and the serious games and pedagogical strategies used in the course. As these narrow abilities are specifically studied for their links with creativity [43], it would be relevant to know more precisely how to foster and develop them.

\section{CONCLUSION}

Rather than pursuing a global goal of 'fostering creativity,' professors need to be conscious of which aspects of creativity they wish to develop, and which activity is likely to succeed. Students need to understand in a more specific and concrete way the objective of their learning [1]. We believe that creativity development has a promising future.

Important aspects of education are the capacity for transfer and the long-lasting repercussions. This study does not follow the students beyond the course to see if the lessons are remembered and used to produce innovation. We are not able to predict or guarantee the long-term effects of the course. Creativity should be viewed as a tool in a toolbox that individual will use and develop throughout their lives as much (or as little) as they need to.

In sum, this educational experience allowed students to become more knowledgeable creative individuals on numerous levels. The course helped learners notably to increase their general knowledge about creativity, develop cognitive abilities underlying creativity and adopt a metacognitive approach. We think the course actively participates in fulfilling the need to train engineers to be more creative. However, even though the course is a definite step in the right direction, the integration of creativity as a skill to develop in the overall engineering curriculum must become an establishment priority to have a real, profound and long-lasting impact on future engineers. This remains a complex matter to attend.

\section{Acknowledgements}

We are grateful for funding to the first author from the Fonds de recherche du Québec - Nature et technologies (FRQNT). We are grateful for funding to the second and third authors from the Natural Sciences and Engineering Research Council of Canada.

\section{References}

[1] A. J. Cropley and K. K. Urban, "Programs and Strategies for Nurturing Creativity," in International handbook of giftedness and talent, K. A. Heller, F. J. Mönks, R. J. Sternberg, and R. 
F. Subotnik, Eds., ed Oxford: Permagon, 2000, pp. 481-494.

[2] Y.-C. Yeh, "Research and Methods," in Encyclopedia of Creativity. vol. 2, M. Runco and S. Pritzker, Eds., ed USA: Academic Press, 2011, pp. 291-298.

[3] Z. E. Liu and D. J. Schönwetter, "Teaching Creativity in Engineering," International Journal of Engineering Education, vol. 20, pp. 801-808, 2004.

[4] D. H. Cropley and A. J. Cropley, "Fostering Creativity in Engineering Undergraduates," High Ability Studies, vol. 11, pp. 207-219, 2000.

[5] R. Felder, "On Creating Creative Engineers," Engineering Education, vol. 77, pp. 222-227, 1987.

[6] I. Badran, "Enhancing creativity and innovation in engineering education," European J. of Engin. Education, vol. 35, pp. 573-585, 2007.

[7] D. Gangopadhyay, "The Dawn of the Creative Age: Fostering Creativity Among Engineering Students," Teaching Innovation Projects, vol. 4, p. Art. 4, 2014.

[8] S. Zappe, T. Litzinger, and S. Hunter, "Integrating the Creative Process into Engineering Courses: Description and Assessment of a Faculty Workshop," in Annual Conference of the American Society for Engineering Education, San Antonio, TX, 2012, pp. 1-15.

[9] S. Zappe, I. Mena, and T. Litzinger, "Creativity is Not a Purple Dragon," in OPEN 2013, NCIIA's 17th Annual Conference, Washington, DC, 2013, pp. 1-13.

[10] M. Murdock and S. Keller-Mathers, "Programs and Courses in Creativity," in Encyclopedia of Creativity. vol. 2, M. Runco and S. Pritzker, Eds., ed USA: Academic Press, 2011, pp. 266270.

[11] Engineers Canada, "Canadian Engineering Accreditation Board : Accreditation Criteria and Procedures," ed. Ottawa, Canada, 2014, p. 118.

[12] A. Johri, H. L. Chen, and M. Lande, "Creativity and Cognition in Engineering Design: Theoretical and Pedagogical Issues," in Seventh ACM Conference on Creativity and Cognition Berkeley, Californie, 2009, pp. 487-488.

[13] G. Scott, L. E. Leritz, and M. D. Mumford, "The effectiveness of creativity training: A quantitative review," Creativity Research Journal, vol. 16, pp. 361-388, 2004.

[14] G. Scott, L. E. Leritz, and M. D. Mumford, "Types of creativity training: Approaches and their effectiveness," The Journal of Creative Behavior, vol. 38, pp. 149-179, 2004.
R. K. Sawyer, The Science of Human Innovation : Explaining Creativity, 2nd ed. USA: Oxford University Press, 2012.

S. R. Daly, E. A. Mosyjowski, and C. M. Seifert, "Teaching Creativity in Engineering Courses," Journal of Engineering Education, vol. 103, pp. 417-449, 2014.

D. H. Cropley, "Title," unpublished|.

T. M. Amabile, "A model of creativity and innovation in organizations." vol. 10, B. M. Staw and L. L. Cummings, Eds., ed Greenwich, CT: JAI Press, 1988.

R. Sternberg, "The Nature of Creativity," Creativity Research Journal, vol. 18, pp. 87-98, 2006.

M. Csikszentmihalyi, "The Creative Personality," Psychology Today, vol. 29, pp. 3640, 1996.

S. G. Isaksen, "Methodolgy for Bridging the Brain and Body for Briliant Innovations," in Methodolgy for Bridging the Brain and Body for Briliant Innovations, À. C. !!, Ed., ed, 1995, pp. 145-181.

L. Gabora, "Revenge of the 'neurds': Characterizing creative thought in terms of the structure and dynamics of human memory," Creativity Research Journal, vol. 22, pp. 1-13, 2010.

L. Gabora, "Creative thought as a non-Darwinian evolutionary process," Journal of Creative Behavior, vol. 39, pp. 262-283, 2005.

L. Gabora, "Honing theory: A complex systems framework for creativity.," Nonlinear Dynamics, Psychology, and Life Sciences, vol. 21, pp. 3588, 2017.

D. J. Treffinger, G. C. Young, E. C. Selby, and C. Shepardson, "Assessing Creativity: A Guide for Educators," National Research Center on the Gifted and Talented, University of Connecticut 2002.

E. C. Nusbaum and P. J. Silvia, "Are intelligence and creativity really so different? Fluid intelligence, executive processes, and strategy use in divergent thinking," Intelligence, vol. 39, pp. 36-45, 2011.

C. Charyton and J. A. Merrill, "Assessing General Creativity and Creative Engineering Design in First Year Engineering Students," Journal of Engineering Education, vol. 98, pp. 145-156, 2009.

C. Charyton, R. J. Jagacinski, J. A. Merrill, W. Clifton, and S. Dedios, "Assessing Creativity Specific to Engineering with the Revised Creative Engineering Design Assessment," J. of Engineering Education, vol. 100, pp. 778-799, 2011. 
[29] C. Charyton, R. J. Jagacinski, and J. A. Merrill, "CEDA: A Research Instrument for Creative Engineering Design Assessment," Psychology of Aesthetics, Creativity, and the Arts, vol. 2, pp. 147-154, 2008.

[30] C. Charyton, Creative Engineering Design Assessment: Background, Directions, Manual, Scoring Guide and Uses: Springer London, 2014.

[31] S. Morin, L.-M. Bourdeau, and J.-M. Robert, "Using the "Gauge R\&R"' method to assess a psychometric creativity test. ," Testing, Psychometrics, Methodology in Applied Psychology, vol. 24, pp. 499-514, 2017.

[32] M. B. Miles and A. M. Huberman, Analyse des données qualitatives: De Boeck, 2003.

[33] R. K. Sawyer, Zig Zag : the surprising path to greater creativity, 1st ed. USA: Jossey-Bass, 2013.

[34] N. Jaušovec, "Metacognition," in Encyclopedia of Creativity. vol. 2, M. Runco and S. Pritzker, Eds., ed USA: Academic Press, 2011, pp. 107112.

[35] J. A. Glover, "A Creativity-Training Workshop: Short-Term, Long-Term, and Transfer Effects," Journal of Genetic Psychology, vol. 136, pp. 316, 1980.

[36] M. M. Clapham, "Ideational Skills Training: A Key Element in Creativity Training Programs," Creativity Research Journal, vol. 10, pp. 33-44, 1997.

[37] R. Legendre, Dictionnaire actuel de l'éducation. Montréal, CA: Guérin, 2005.

[38] L. S. Vygotsky, Mind in Society: The Development of Higher Psychological Processes. Cambridge, MA: Harvard University Press, 1978.

[39] C.-. Chang, L.-P. Peng, J.-S. Lin, and C. Liang, "Predicting the creativity of design majors based on the interaction of diverse personality traits," Innovations in Education and Teaching International, 2014.

[40] M. Bateya, T. Chamorro-Premuzicb, and A. Furnham, "Intelligence and personality as predictors of divergent thinking: The role of general, fluid and crystallised intelligence," Thinking Skills and Creativity, vol. 4, pp. 60-69, 2009.

[41] C. D. Wickens, Engineering Psychology and Human Performance. Michigan, 1984.

[42] D. Norman, "Distributed Cognition," in Things that make us smart., ed USA: Perseus Books, 1993, p. 290.

[43] M. J. Avitia and J. C. Kaufman, "Beyond g and c: The Relationship of Rated Creativity to LongTerm Storage and Retrieval (Glr)," Psychology of Aesthetics, Creativity and the Arts, vol. 8, pp. 293-302, 2014. 